\title{
LA MOVILIDAD Y EL HABITAR CHILOTE. CAMBIOS, RUPTURAS Y CONTINUIDADES EN LAS PRÁCTICAS DE MOVILIDAD COTIDIANA DE LOS HABITANTES DEL ARCHIPIÉLAGO DE CHILOÉ, EN EL SUR AUSTRAL DE CHILE
}

\author{
MOBILITY AND HABITATION IN CHILOÉ: CHANGES, DISCONTINUITIES AND \\ CONTINUITIES IN THE MOBILITY PRACTICES OF THE INHABITANTS OF THE \\ CHILOÉ ARCHIPELAGO IN SOUTHERN CHILE
}

\author{
Alejandra Lazo y Diego Carvajal ${ }^{2}$
}

\begin{abstract}
Tomando como punto de partida el concepto de constelación propuesto por Cresswell, y por medio de una investigación realizada en el archipiélago de Chiloé, sur austral de Chile, se plantea identificar distintos tipos de constelaciones de movilidad que varían desde formas tradicionales regidas por ritmos atmosféricos y estacionales, expresadas en lo colectivo y recíproco, hasta movilidades más proletarizadas, rápidas y urbanas. Se discutirá la hipótesis de que existen diferentes constelaciones de movilidad que entran en tensión y que constituyen "el habitar chilote actual". En definitiva, la movilidad cotidiana de los habitantes de Chiloé se comprenderá desde sus cambios, tensiones y permanencias como reveladores de las transformaciones políticas, económicas y sociales acaecidas en las últimas décadas en el territorio insular.

Palabras claves: constelaciones de movilidad, habitar, archipiélago de Chiloé.
\end{abstract}

Taking Cresswell's concept of constellation as a starting point, and through research carried out in the Chiloé Archipelago in southern Chile, this study suggests that it is possible to identify different types of mobility constellations that vary from traditional forms regulated atmospherically and seasonally, and expressed in the collective and reciprocal dimensions, to more proletarianized mobilities, which are faster and more urban. The hypothesis that there are diverse constellations in tension that constitute "the current habitation in Chiloé" will be discussed. Ultimately, the daily mobility of the Chiloe inhabitants will be understood based on its changes, tensions and continuities, as revealing aspects of the political, economic and social transformations that have taken place over the last decades in this insular territory.

Key words: Mobility constellations, habitation, Chiloé Archipelago.

\section{El Rol del Movimiento en la Constitución de las Culturas y los Territorios Rurales}

En la última década se asiste a un vuelco en la literatura de las Ciencias Sociales que para algunos autores constituye un "giro hacia la movilidad" (Cresswell 2006; Sheller y Urry 2006; Urry 2007) debido a la creciente importancia del movimiento en el análisis de los procesos sociales, demostrando como la movilidad posee un papel fundamental en la generación de la subjetividad, la organización social y el lugar (Adey 2009; Hannam et al. 2006). A pesar de ello, se constata que la mayor parte de las investigaciones sobre movilidad (Bissell 2009; Sheller 2007; Urry 2007; Watts 2008) se centran principalmente en espacios urbanos continentales y subcontinentales, omitiendo los procesos de movimiento de personas, objetos, imágenes y discursos que ocurren en los mares, costas, islas y archipiélagos (Vannini et al. 2009).

Bajo esta constatación, el presente artículo pone en evidencia que las comunidades isleñas en general (Baldacchino 2007a, 2007b; Baldacchino y Clark 2013; King 2007; Vannini 2012a, 2011a, 2011b), y en específico en el caso de Chiloé (Mansilla 2009a, 2009b; Ther 2008, 2011), no han estado ajenas a

\footnotetext{
CEDER- Universidad de Los Lagos. Osorno, Chile. alejandra.lazo@ulagos.cl

Universidad de Chile. Santiago, Chile. diegocarvajalhicks@gmail.com
}

Recibido: noviembre 2016. Aceptado: diciembre 2017.

http://dx.doi.org/10.4067/S0717-73562018005000203. Publicado en línea: 21-febrero-2018. 
las presiones y exigencias de la movilidad viéndose en las últimas décadas enfrentadas a importantes transformaciones espacio-temporales. Como bien señalan Bell y Osti "la movilidad es fundamental para la expansión de la población rural. Mercados, empleos, compras, vida social, educación, ir a la iglesia, ir a ver a un médico, visitar parques. Para todo esto se requiere atravesar el espacio y a menudo grandes alcances del mismo, si uno vive en un lugar rural o está viajando a uno. Desde esta perspectiva, es razonable afirmar que la población rural es al menos tan móvil como lo urbano, si no más" (Bell y Osti 2010:199).

Para este artículo tomaremos el caso del archipiélago de Chiloé en el sur austral de Chile. Este archipiélago intensamente recortado y fragmentado en innumerables islas, se encuentra separado del continente al norte por el canal de Chacao y está compuesto de un mar interior, el golfo de Ancud y el Corcovado. Esta es una isla grande, la segunda más grande del país en superficie, reuniendo a cerca de 155.000 habitantes; dos ciudades principales, Castro al este y Ancud al norte; y varias islas secundarias dispersas por el Golfo.

Lo que se presenta a continuación surge de los resultados de un proyecto de investigación donde se estudió la movilidad cotidiana de los habitantes del archipiélago de Chiloé y sus islas. Queremos especificar que si bien el proyecto se enfocó en el archipiélago de Quinchao, lo que se presenta a continuación es extrapolable al contexto de Chiloé en general, y esto lo podemos afirmar a partir de las conversaciones y entrevistas que fueron realizadas con distintos actores y en distintos rincones del archipiélago, así como a partir de la revisión de fuentes bibliográficas relativas a los cambios y transformaciones sufridas en la movilidad de los Chilotes en las últimas décadas (Mansilla 2009a, 2009b).

En efecto, para el caso de Chiloé, intentaremos demostrar como la movilidad es parte de la cotidianeidad y se hace una condición necesaria del habitar isleño. Es por ello que cambios políticos, económicos y sociales que ocurren en estos contextos sin duda afectan la forma de habitar el territorio. Considerando lo anterior, y porque existen pocas investigaciones que dan cuenta de este aspecto en el mundo rural, consideramos pertinente acercarse desde un enfoque antropológico a lo que sucede con la movilidad, identificando cambios, tensiones y coexistencias en la manera de moverse por el territorio insular. De este modo, se espera contribuir a las dinámicas de los espacios litorales e insulares a partir del concepto de "constelación de movilidad" (Cresswell 2010) como clave para leer dinámicas socio-territoriales en curso en el mundo archipelágico actual.

Hemos dividido este artículo en una breve introducción de lo que entendemos por constelaciones de movilidad y su importancia analítica en el habitar chilote. Luego, describiremos las constelaciones identificadas en Chiloé a partir del análisis de los discursos, prácticas, experiencias y sentidos de movilidad propios de cada época. Terminaremos problematizando la importancia de comprender la movilidad como una evidencia que nos permite leer los principales cambios, rupturas y continuidades acaecidos en el habitar chilote, dando cuenta de la tensión latente entre tradición y modernidad.

\section{Las Constelaciones Como Clave de Lectura para la Movilidad Archipelágica}

Retomando el concepto de "constelación" de Cresswell, la movilidad en Chiloé será entendida como un "conjunto de formaciones históricas y geográficas específicas de movimiento, narrativas sobre la movilidad y prácticas de movilidad" (Cresswell 2010:5). En este sentido, el movimiento físico (como se llega desde un lugar a otro), las significaciones del movimiento (discursos, narrativas e historias sobre el movimiento) y la experiencia de la práctica de ese movimiento, serán elementos centrales para la comprensión de las movilidades isleñas.

En primer lugar, el movimiento se relaciona con el lugar y con la experiencia. Cresswell (2010) identifica como centrales en este punto, la finalidad o propósito de viaje, la velocidad, el ritmo, las rutas y escala espacial. En segundo lugar, las movilidades son significativas, es decir, significan cosas diferentes para diferentes personas en contextos sociales, culturales e históricos. Por ejemplo, el mismo viaje para propósitos diferentes adquiere distintos significados, como por ejemplo el turismo, la inmigración o trámite cotidiano. Finalmente, las movilidades son prácticas. Esto quiere decir que la práctica de movimiento puede variar dependiendo de diversos factores, subjetividades y espacios. En circunstancias diversas, la práctica de movimiento puede ser una experiencia estimulante, o ser una rutina aburrida o una aventura que amenaza la vida.

Cresswell (2010), argumenta que los significados dados a ciertas formas de movilidad, son cultural y socialmente codificados. En este sentido, no se debe olvidar considerar en el análisis la cuestión del poder, donde muchas veces las movilidades de las clases dominantes, de quienes manejan los recursos económicos, ocurren a expensas de la inmovilidad de las clases subalternas, 
específicamente forzándolas a confinamientos, movilidades forzadas o pseudomovilidades. En el caso de Chiloé, por ejemplo, las movilidades que implicaría la construcción del puente de Chacao aparecen como una necesidad que viene desde las empresas y transnacionales instaladas en el territorio y no relacionadas con los requerimientos de los habitantes de Chiloé (Anabalón 2017; Henríquez et al. 2015). Es así que no se debe perder de vista el marco económico capitalista donde están inscritas las poblaciones y los territorios, que en el caso de Chiloé, son relevantes para observar las formas de dominación que están implícitas en la movilización de recursos, mercancías, poblaciones y capitales (Calonge 2014).

Un análisis de las movilidades en Chiloé, no sólo debe considerar las distancias y tiempos recorridos sino que también los discursos, los significados y las prácticas que permiten integrar tanto los cambios como las permanencias.

\section{Entre lo colectivo, la proletarización y la individualización}

Las tres constelaciones de movilidad que presentaremos y que coexisten hoy en el archipiélago de Chiloé, nos ayudan a agrupar e identificar, desde una perspectiva temporal, el movimiento físico y las relaciones geográficas (movilidad desde el archipiélago), los significados que tiene y ha tenido el movimiento (discursos, narraciones e historias sobre la circulación y migración isleño/ continental) y las prácticas y objetos involucrados en la experiencia de moverse.

\section{Primera constelación: movilidad y migración a la Patagonia}

Identificamos que uno de los elementos que ha caracterizado a las comunidades del mundo rural y específicamente a los habitantes del archipiélago de Chiloé es el movimiento. Los habitantes de las islas y de la ruralidad archipelágica han necesitado del contacto con el mundo exterior para poder sobrevivir, es por ello que a causa de su insularidad, el movimiento y el viaje forman parte de su vida cotidiana. Baldacchino (2003) identifica que los isleños manifiestan que su modo de vida y su identidad tienen mucho que ver con la insularidad y el aislamiento, pero también con la migración y la movilidad.

La primera constelación identificada estará caracterizada por la gente más antigua del archipiélago de Chiloé y que vivió en la segunda mitad del siglo $\mathrm{XX}$. Los viajes cotidianos se realizaban en lanchas a remo, y posteriormente a vela, varias veces al año, desde las islas del mar interior hasta los centros poblados más importantes para comercializar, vender, producir y abastecerse. Generalmente se salía muy temprano en la mañana para llegar varias horas después a ciudades como Castro o Ancud. Muchas veces el viaje podía durar días enteros, dependiendo de las condiciones climáticas.

Junto a los viajes cotidianos para abastecerse, eran en esta época muy frecuentes los viajes a la Patagonia donde jóvenes y hombres de las islas viajaban a trabajar en las estancias durante la temporada de esquila de ovejas y retornaban luego de algunos meses a sus islas con el dinero para vivir el resto del año (Yáñez 2011). Los Chilotes eran conocidos en la Patagonia por ser trabajadores, se adaptaban rápido y tenían mucha fuerza. El fenómeno migratorio fue clave en la identidad del chilote e involucró especialmente a la población de las islas inmediatas a Castro y poblados cercanos a Ancud.

Siendo Puerto Natales el límite fronterizo desde Chile, estas migraciones se concentraban principalmente en ciudades como Rio Gallegos, Puerto Santa Cruz y Comodoro Rivadavia y se establecían bajo una triple temporalidad ligada al trabajo agroindustrial, de corto, mediano y largo plazo (Gundermann et al. 2009). Hacia los años setenta del siglo pasado, las oleadas de chilotes en Magallanes dejaron entre un 20\% y $30 \%$ de descendientes y la mitad de la población actual en la zona tiene relación con Chiloé (Montiel 2007).

En esta época el viaje por mar y el enfrentamiento del chilote con la naturaleza patagónica formaba parte de un imaginario complejo y sobre todo "de hombres", donde se mezclaba la mitología, el paso a la adultez, el prestigio y el ideal errante del viajero (Mancilla y Rehbein 2007). Las migraciones a Chile continental cumplían la función de "convertirlos en hombre" (Macé 2010:14) ya que eran viajes que los hombres jóvenes realizaban a lugares desconocidos, sin amigos ni familia, y donde debían adaptarse a lo que allí encontraban.

Las mujeres de esa época, en cambio, no formaban parte de este imaginario sino que ellas eran los anclajes quienes se quedaban a cargo de la casa y la familia, al mismo tiempo que debían trabajar en el campo, cuidar a los animales, cuidar el huerto y recolectar mariscos durante la ausencia del hombre. Como plantea Macé, "el espacio de las mujeres estaba en el interior" (Macé 2010:14) a diferencia del cuerpo masculino que, estando afuera incluso, controlaba el espacio y era frontera del anclaje doméstico.

Por último, el estatus del hombre chilote comenzó a definirse más por su patrimonio económico que por la personalidad y el "trabajo 
duro" (Macé 2010). Ello, marcará el paso a la siguiente constelación, en tanto se empieza a situar el trabajo como objeto de acumulación, poniendo en ruptura otra espacialidad, esta vez del trabajo y el género en las islas.

Durante este periodo, el gobierno chileno inspirado en la presunta miseria de Chiloé impulsó la emigración, ocupando periódicamente sus transportes para trasladar chilotes a Punta Arenas (Mancilla y Rehbein 2007). Sin embargo, una de las razones fundamentales del Estado para fomentar las migraciones de chilotes hacia otras zonas, era su enorme capacidad de adaptarse a las condiciones naturales y de trabajo más adversas. Del mismo modo, el desarrollo migratorio desde Chiloé a la Patagonia, da cuenta de la inserción de más población a un territorio para el trabajo de la lana y el ovino.

De esta forma, se señala que:

El chilote, errante por naturaleza, ha recorrido otras tierras y ha visto que allí puede surgir, haciendo valer sus títulos de gloria: la constancia y el espíritu de ahorro; el ejemplo de otros que han surgido fuera de su tierra, es además otro aliciente poderoso para su determinación a abandonar su terruño querido (...) (Mansilla y Rehbein 2007:108).

Yáñez (2011) señala sin embargo, que el trabajo que iban a realizar los chilotes fuera del archipiélago se desarrollaba con muy pocas garantías y sin contrato laboral. Muchos habían realizado un gran esfuerzo para llegar ahí y sólo querían cumplir con el deseo de ganar dinero, no importando el cómo.

En relación con el vínculo de los chilotes y su medio ambiente, podemos mencionar que muchos jóvenes envueltos en este imaginario de la aventura y en el desafío de hacerse hombres, aprendieron desde pequeños las maniobras de navegación, conocían las artes de navegar, no le tenían miedo al mar. Tal como se plantea a continuación:

... el chilote es buen navegante, aquí toda la gente por el hecho de vivir a orilla de mar o rodeado de mar o vivir dentro de las islas, me acuerdo estuve viviendo dentro de las islas del grupo Desertores por allá por donde está la isla Talcán y toda esa zona de islas por ahí, los chicos como la edad de (...) 13-14 años salen a navegar por ahí por los canales con sus botes, a maniobrar la vela, a correr contra el viento, a aprender toda esa maniobra, (...) son expertos para el tema de la vela (...) y todo el día lo pasan en eso no más, increíble que hay gente que se maneja con tremendos chalupones de 15 metros veleros (...). Son muy buen navegantes muy buen marino, las necesidades hace que se aprenda (Mansilla y Rebhein 2007:104-105).

En estas prácticas, la movilidad, la migración y un chilote envuelto en su medio, irán marcando el precedente para nuevas generaciones que optan por el movimiento desde el archipiélago a otros lugares o dentro de la propia isla. Esto dice relación, ya desde los años sesenta del siglo pasado, con el paso hacia economías internacionales o globales, donde van cambiando las formas de producción tradicionales, la relación espacio-tiempo (Floysand y Román 2008; Mansilla 2006) y el medio ambiente, empujando a los chilotes hacia nuevas prácticas de movilidad.

\section{Segunda constelación: proletarización e individualización de los isleños}

La segunda constelación la situamos a inicios de la década de 1980 del siglo XX, cuando ocurre una transformación productiva en Chiloé en la cual se da paso desde una economía de subsistencia a una economía de escala global, a partir de la instalación de la industria acuícola en el territorio. Ello hizo que muchos chilotes se convirtieran en trabajadores asalariados que recibían un dinero mes a mes, lo cual les abrió las puertas a nuevos territorios y bienes de consumo que antes eran casi inexistentes.

Primero fue lo de la agricultura que fue desapareciendo, como le dije, y después vino el boom de la salmonera, aquí hubo una planta que contrató mucha gente, eso hizo que la gente descuidara más su agricultura y se fuera a trabajar a la salmonicultura. Pero, pasado el tiempo eso vino a saturar la playa, el medio ambiente y toda la costa, entonces fueron cerrando los centros y fueron despidiendo a la gente; esa gente que estaba ya acostumbrada a vivir con su sueldecito no quiso seguir viviendo del campo, entonces visualizó las industrias que están en Dalcahue y para allá partieron porque se había acostumbrado a vivir del sueldo (salario) (Entrevista hombre adulto, isla de Quenac, archipiélago de Quinchao).

Este nuevo sujeto identificado con el trabajo y con sus bienes, va adquiriendo teléfonos celulares, electrodomésticos, televisores, artículos para el hogar. Todo esto comenzó a circular de forma común en el archipiélago y en las islas menores. 
En este panorama, ya no se veía como necesario el viaje de los hombres a la Patagonia pues ahora podían optar a los empleos más cercanos y de carácter técnico. Al mismo tiempo, muchas mujeres optaron por primera vez a un trabajo asalariado sin tener que descuidar las labores domésticas, acercándolas a una mayor autonomía e independencia, tanto económica como espacial. Esto no fue siempre fácil, implicaba entrar muchas veces en las dinámicas de la pobreza urbana:

... Igual no les ha ido bien porque no es fácil la vida, porque Achao es un pueblo muerto, usted lo ve, no tiene fuente de trabajo además de estos que llegaron, las empresas que pagan poco. Y las mujeres que se han ido de aquí se han tenido que dedicar al trabajo de la municipalidad que le da, esto cómo es que se llama, por tres meses, pero es un trabajo que igual es sacrificado porque ganan el mínimo (...) las chicas que se fueron tuvieron que comprar zanahorias, las papas y hasta el diente de ajo pa parar la olla (Entrevista mujer adulta, isla de Llingua, archipiélago de Quinchao).

Sin embargo, la conquista del espacio a partir de la mayor movilidad de las mujeres es importante, produciéndose un desplazamiento de lo privado a lo público cada vez más evidente que se expresa tanto en la experiencia de la movilidad y el emplazamiento territorial, así como en la organización social isleña (comunitaria o turística). Lo anterior se observa en el trabajo cotidiano, por ejemplo, en el mercado de Achao, donde muchas mujeres mayores trabajan vendiendo sus productos, acompañadas de sus hijas a quienes les enseñan la tradición textil fuera del espacio doméstico de la casa, lo que constituye una ruptura a una movilidad reducida históricamente al hogar.

En términos generales, las oportunidades de trabajo local impactan en el rol de muchos de los hombres de Chiloé, por cuanto sus migraciones a Chile continental ya no son necesarias. La llegada de la mayoría de edad y la entrada en la edad adulta que estos viajes representaban se pierde cuando los hombres tienen acceso a oportunidades de trabajo local en la industria del salmón. En esta transición de producción en el territorio, los hombres pierden en la práctica, su identidad como viajeros y, a menudo, su rol como los únicos proveedores de ingreso económico para la familia (Macé 2010) para transformarse en obreros de fábrica. De este modo, y a pesar del recuerdo de estas prácticas, la migración de antaño es remplazada por la movilidad hacia la ciudad y los centros más poblados de Chiloé.

La analogía con los viajeros de la Patagonia es evidente, explica Gobantes (2011), y aparece entre los entrevistados el imaginario de la migración ruralurbana. Resuenan aquí descripciones tales como "aventurarse a la ciudad", "enfrentar la adversidad", "probarse que uno es capaz" (Gobantes 2011).

Mientras algunos campesinos encontraron un trabajo complementario con la vida rural, son muchos más los que se han proletarizado empleándose en las plantas industriales y servicios que en la mayoría de los casos requiere trasladarse a los centros urbanos. Esto, junto a una disminución de la calidad de vida y en algunos grupos, el acercamiento a la "pobreza urbana" expresada en la vivienda, en su materialidad ligera y en limitaciones de condiciones básicas (Jordán y Martínez 2009). Muchos chilotes tienen que comprar la papa, el ajo y otros alimentos que antes podían cultivar en sus propios huertos. Otros vendieron sus predios para vivir en pequeñas casas con techos de zinc remplazando la tradicional tejuela y donde no tienen patio, ni animales. En ese sentido es que también, los pocos negocios en cada isla, tengan precios no muy convenientes para economías familiares. Cuestión que obliga al movimiento y el abastecimiento para mayores cantidades de tiempo y almacenamiento.

Por otro lado, el ingreso acelerado de una industria global en un territorio insular donde aún priman relaciones de reciprocidad junto con una agricultura para el autoconsumo, tuvo consecuencias sobre los objetos que circulaban cotidianamente. En un principio, en los años ochenta y noventa fue la radio, la televisión, el teléfono, el "personal estéreo"; luego vino el consumo masivo, las tarjetas de crédito y con ello el acceso a celulares, televisores, notebooks, mp3, ropa de marca, entre otros. Esto sobre todo en las zonas más urbanas de Chiloé.

Gobantes (2011) haciendo una analogía con los objetos que caracterizaban a los migrantes de la Patagonia, y a la entrada de la radio y la televisión en los años 1960, hace referencia a los trabajadores del salmón: "chaquetas Columbia, zapatos Caterpillar, camioneta, celular, etc." (Gobantes 2011:78).

Se postula que la industria del salmón marcó la entrada de Chiloé a una economía global de mercado a la que aspiraban no sólo quienes trabajaban en las fábricas, sino que también muchos jóvenes y mujeres de la isla.

Mira si acá en Chiloé, yo creo que lo que salva, lo que salva...son las salmoneras...si 
ni hubiera salmoneras...por eso me da rabia cuando alegan...con la contaminación... que esto, que lo otro...ya.... lo mejor si es verdad que contaminan las playas...y eso, pero igual es bueno... (Entrevista mujer joven, isla de Apiao, archipiélago de Quinchao).

La industria del salmón dio paso a una movilidad antes imposible, asociada a la posibilidad de superar el aislamiento rural y participar de un contacto social, cultural y material que venía de afuera. Ello condujo a una fuerte movilidad residencial sobre todo de los más jóvenes, quienes han dejado sus casas y se han mudado a las ciudades y pueblos del archipiélago en busca de mejores oportunidades con el consiguiente despoblamiento de las islas. Cabe mencionar que muchos jóvenes de distintas comunidades del archipiélago son presionados a salir por sus familias y por un entorno que también, no tiene desarrollo o "expresión juvenil" en sus espacios, y donde el estar ahí, siendo productivo, parece una contradicción.

Según Yáñez (2011) varios de estos cambios también se reflejan en el paso de una sociedad de remeros a una sociedad que ahora viaja en lanchas a motor. Una sociedad que fue dando paso a otra de pasajeros, caracterizada por trabajadores obreros con menor capacidad asociativa y mayores elementos propios de la modernidad. La individualización de los isleños, en su fijación siempre hacia afuera, trae consigo el desinterés ante la privatización del mar, así como de los efectos ambientales.

Los viajeros, que en la constelación anterior eran remeros y que viajaban largas horas en botes a remo o lanchas veleras -resolviendo cooperativamente todos los problemas del viaje-, se transformaron en usuarios de un medio de transporte pagado. Lo anterior, implicó que comenzaran a cancelar un valor de dinero estable por el pasaje y, paulatinamente, se fue consolidando una relación de clientes respecto al dueño de la lancha y su tripulación. No había que preocuparse de los eventuales problemas del trayecto, sólo pagar el pasaje y estar en el puerto a la hora de salida.

Estos cambios en la movilidad cotidiana de los chilotes se condicen con los cambios socioculturales ocurridos en las últimas décadas. El trabajo comunitario propio de medanes y mingas se transformó en trabajo asalariado individual. Esto último implicó, tras el cierre de las empresas luego de la crisis que tuvo el sector en el 2007 con el virus ISA, una fuerte migración a la ciudad ampliando allí los problemas propios de la urbe tales como el desempleo y el trabajo precario. La mayoría de los jóvenes emigró a Castro, y junto a eso el individualismo de la modernidad parece conquistar los espacios sociales de la comunidad.

Se puede observar como en esta segunda constelación van desapareciendo algunos elementos típicos relacionados con la forma de moverse tradicional de los chilotes para adoptar formas que están relacionadas con la vida urbana, donde la rapidez y la inmediatez comienzan a ganar espacio, y se da paso a la siguiente constelación. El reloj, la entrada a la fábrica, los horarios del trabajo, las preocupaciones económicas pasan a regir el ritmo cotidiano y la necesidad de movilidad de los chilotes. Esto sin embargo cambia en relación a la condición y desarrollo de cada isla, así como de forma singular en las experiencias de cada comunidad/isla/personas, las formas de capitalizar y ejercer nuevas formas de movilidad. Es así como por ejemplo, la fluidez e intensidad en la movilidad estará delimitada por el desarrollo socio-territorial de cada isla, así como influenciada por las redes y estrategias de cada grupo o persona, el acceso y los recursos de movilidad que se disponga.

\section{Tercera constelación: los artefactos de la globalización y el deseo de dejar el archipiélago}

Esta tercera constelación es la más difícil de caracterizar ya que tiene elementos comunes con las otras dos constelaciones, pero los moviliza dentro del marco económico capitalista ya instalado en el archipiélago.

En la actualidad el archipiélago de Chiloé se encuentra bien conectado y orientado al mundo mediante el comercio, la migración, el turismo, y las importaciones bióticas, culturales y materiales. Sin ello, las islas y las formas de vida que contienen simplemente no sobrevivirían (Baldacchino 2004; Clifford 1997). En el contexto de esta constelación, la movilidad de los chilotes pasa a ser una movilidad ubicada en los tiempos más rápidos de la modernidad, ocupando más tecnología y más dependiente de factores externos.

En el caso del archipiélago de Chiloé se observa con asombro la llegada de los llamados "artefactos de la globalización" (De Mattos 2006): tecnología móvil, movilidad mejorada por autopistas, la construcción del emblemático shopping mall de Castro, la construcción del puente, el surgimiento de nuevos barrios residenciales, etc., como objetos que van cambiando el paisaje insular tradicional.

En el caso de las tecnologías, estas van orientando el viaje y coordinando de modo tal que, a diferencia de antes, si la lancha se va sin alguien es posible hacer uso del teléfono celular y definir otra acción a seguir en lo inmediato. 
En ese sentido las tecnologías van programando lo inesperado del viaje isleño y van cambiando también su temporalidad. De todas formas, la conexión a nuevas tecnologías-objetos, en algunas islas aún es relativa, lo que implica por ejemplo estrategias cotidianas para capturar mejores señales y conectar sin problemas con centros más poblados de Chiloé. Cada avance y modernización es empujado hacia adelante por expectativas populares que chocan con otro tipo de prioridades como salud y educación en la isla.

En el caso de los hombres y mujeres sus movilidades parecen equiparse un poco más en esta constelación. Sobre todo las mujeres viven hoy en un mundo rural menos diferenciado del urbano que en tiempos anteriores. Ellas conocen la vida urbana de forma directa, a través de los estudios, el trabajo, amistades, los tramites. Pertenecen a una generación familiarizada a mantener relaciones fluidas entre la isla y el pueblo, a partir de lo cual las opciones son variadas, salir, quedarse, o transitar de un lugar a otro (Gajardo 2015).

Estas rupturas, sin embargo, deben conciliar las relaciones de dominación históricas. Esto se expresa en que la movilidad femenina debe muchas veces, en su carácter colectivo, hacerse cargo y relacionarse corporalmente con todos los objetos que debe trasladar, además de los hijos que deben llevar en cada viaje. Esto hace de la movilidad una experiencia cotidiana siempre ligada a la relación de sus fuerzas y maniobras, y de todas las fricciones como diría Vannini (2011a), que aparecen en cada viaje, en cada larga espera o interrupción del trayecto debido a cuidados familiares.

Los hombres, en cambio, cada vez más esclavos del trabajo que les dan en las grandes empresas instaladas en el territorio y en el comercio de retail han debido soportar "inmovilidades relativas" debidos a periodos de desempleo y cesantía, que les obligan a replegarse en su territorio próximo a la espera de nuevas oportunidades, ya que hoy dependen de un trabajo asalariado y no del trabajo de la tierra y el mar.

Por otro lado, y junto a las movilidades de los isleños también surgen otras movilidades que vienen de afuera. Se trata de los visitantes y turistas bastante afluentes y muchos interesados en invertir en propiedades isleñas, más todavía en lugares donde las propiedades (gracias a los puentes, túneles y calzadas) están sólo a unas pocas horas de conducción del hogar continental.

A esta llegada de personas de afuera se suma, a partir de la construcción del aeropuerto de Mocopulli en el año 2012, la llegada del avión desde la ciudad de Santiago. De este modo, se incrementa el número de personas que llega desde el continente y lo puede hacer incluso por el día.

Ello, también viene a afectar los precios de los bienes raíces, los que pueden crecer para alcanzar esta nueva demanda y precio que, excede lo local y relación familiar con sus tierras. La "gentrificacion" (Berry 1985; Clark et al. 2007; Glass 1964), lleva a un aburguesamiento de la sociedad anfitriona en la isla, marginalizando gradualmente a los habitantes más pobres. En el caso de Chiloé se puede observar como muchos de los palafitos de la ciudad de Castro fueron comprados por gente de afuera de la isla y transformados en hostales boutique, restaurantes y cafés. Las ciudades principales del archipiélago ahora tienen "casas de cambio de dinero" para los turistas, gimnasios para acercarse a prototipos de cuerpos y tiempos globales, tiendas de accesorios y ropa de aventura para el "turismo sustentable".

Los habitantes originarios se ven entonces obligados a vender o mudarse para así asegurar un alojamiento que esté al alcance de sus recursos. La gentrificación también tensiona los discursos en torno a la actualidad chilota. Entre un movimiento social más ilustrado, acomodado, crítico, producto de la misma gentrificación y su emplazamiento cultural en la isla, y un chilote más arraigado, que apoya la integración espacial por cualquier medio, para el progreso isleño. Desarrollo que, paradójicamente se instala al alero del despoblamiento y ruptura con el espacio tradicional re-valorizado.

Otra de las características de esta constelación es el aumento de la migración hacia los centros poblados más cercanos de la isla. Si bien esto había comenzado en la constelación anterior, hoy se ha intensificado llevando al surgimiento de periferias en los alrededores de centros urbanos como Castro, Ancud o Quellón. Aquí los isleños viven en viviendas muy pequeñas y que muchas veces no cuentan con los servicios básicos. Como plantea Barton, la velocidad de la modernidad urbana y su cálculo económico, difiere del desarrollo local de infraestructuras o equipamientos así como de políticas sustentables y normativas en torno a los suelos donde se emplazan las zonas residenciales (Barton, Pozo et al. 2013).

Por otra parte, se constata entre los jóvenes como la forma de acercarse e integrarse a la modernidad del continente, es por medio de su exploración e instalación a partir del trabajo o estudio. Esto opera con fuerza en la actualidad de los jóvenes chilotes que en su mayoría tiene por aspiración y expectativa la salida del archipiélago. Una forma cotidiana de acercamiento a esta aspiración "socio-espacial", es la relación de estos con los 
nuevos objetos tecnológicos y con el imaginario de integración que estos dispositivos promueven desde su uso. Es así como en la relación de los nuevos objetos tecnológicos con los isleños, se van estableciendo nuevas formas, costos y motivos para sortear la fricción (Vannini 2011a) del aislamiento, inmovilidad o lentitud.

Esto se materializará en mayor medida, con la construcción del futuro puente que unirá el continente con la isla donde la tecnología del automóvil conspirará con ella, al transformar identidades locales privilegiando la movilidad por sobre el lugar. Llegaran más personas, mercancías y recursos, en menos tiempo, y con intereses particulares fomentando la movilización rápida del capitalismo en la isla.

Asimismo la llegada del mall a Castro, que por medio de crédito y endeudamiento en la compra, hace que se vayan adquiriendo sin mucha limitación (espacio-temporal) de cuotas, los nuevos objetos tecnológicos del mercado, instalando en la cotidianidad isleña, una oferta de acceso e integración al espacio global. Esta integración espacial, valorada como económica además, deja por resultado que el isleño más arraigado o antiguo por sí mismo, no articule disidencias políticas y/o receptivas críticas ante la avanzada general de modernización y de capitales económicos en la isla. De tal modo que en la actualidad, los isleños que siempre han acostumbrado a moverse en extenso, no escatiman en hacerse parte y viajar hacia los nuevos espacios de la modernidad:

\section{...A Castro casi siempre voy \\ ¿Por qué razones? \\ Para ir a comprar ropa o zapatos, me conviene más porque hay cómo más variedad, por eso voy más a Castro. \\ ¿Y cada cuanto vas? \\ Cada fin de mes, más o menos, me voy a dar una vuelta. \\ ¿Y para ir a Castro como lo haces? \\ En el auto de una amiga nos vamos a Castro (Entrevista a mujer joven, isla de Apiao, archipiélago de Quinchao).}

A medida que exista mayor cercanía a centros urbanos más poblados, es que también las formas y conexiones de movilidad se van haciendo más eficientes, al tiempo que también requieren de otra capacidad de ingresos, como para el caso de vehículos que luego del trayecto en lancha, se pueden abordar dependiendo de las posibilidades individuales de gestión o adquisición personal/familiar.

Finalmente, es posible observar como las diferentes constelaciones de la movilidad se complementan y persisten con sus cambios.
Siguiendo a Barton, Román et al. (2013) concordamos con la evidencia de que gran parte de los modos de vida tradicionales han menguado debido a la proletarización de la población, el cambio en la estructura de ingresos familiares, los cambios en la movilidad, y la mayor inversión extranjera y pública en el territorio. Sin embargo, es posible vislumbrar que aún persiste una cultura chilota que, en muchos casos, sigue asociada a una economía de subsistencia, sobre todo en las islas menores y que se da entre personas mayores y mujeres. Esta complementariedad, "entre lo moderno (teléfonos móviles, vehículos todo terreno, construcción con zinc y no de tejuelas, salarios mensuales) y lo tradicional (producción de subsistencia diversificada, predios familiares, un fuerte sentido identitario como chilotes, y el uso de herramientas y máquinas tradicionales)" (Barton, Román et al. 2013:202) constituye lo que hoy podemos llamar el habitar chilote actual.

\section{Conclusiones. El Habitar Chilote en Tensión}

Si bien se analizaron tres constelaciones de movilidad, reconocemos que existen muchas más que resultan de las distintas combinaciones que se dan entre conexión y desconexión, movilidad e inmovilidad, isla, continente, pasado y modernidad. Sin embargo, una de las primeras cosas que se pueden rescatar de este análisis histórico de las movilidades archipelágicas, es como la entrada del capitalismo a la isla fue un motor importante de cambio, en las formas de habitar tradicionales desde una movilidad archipelágica regida por los ritmos atmosféricos y estacionales, más colectiva y recíproca, hasta una movilidad más rápida, individualista y urbana.

Se constata que este tipo de análisis permite vislumbrar la movilidad en Chiloé desde una perspectiva histórica donde se han ido tejiendo diferentes relatos, discursos, significados y prácticas que han ido a veces cambiando y otras veces permaneciendo. En el caso de Chiloé, hemos visto como en cada época son distintos actores los que tienen el potencial y la capacidad de moverse, diferenciando entre quien se mueve más lejos, quien se mueve más rápido o con más frecuencia. Ello nos habla de relatos fundacionales de la modernidad que se han construido alrededor del hecho de moverse y que a la larga impactan en las prácticas cotidianas de las personas. En el caso de Chiloé, el análisis de la movilidad nos muestra una tensión entre un sentir tradicional del espacio habitado y una estrategia gubernamental de dominación política que se materializa desde la idea de una inclusión incompleta a la modernidad. 
Ello, se traduce en la actualidad en las inversiones extranjeras de empresas globales presentes en el territorio, en el shopping mall de Castro, en la actual construcción del puente de Chacao, en el fomento al turismo a gran escalada, etc., en pos de otros intereses como salud y educación que se encuentran entre las necesidades de los habitantes.

Parece ser que la inclusión modernizante, socio-económica y simbólica es la despolitización del presente chilote y de cierta parte de los simbolismos culturales asociados a la relación progreso y movimiento. Es además una forma de relación con esa urbanidad encarnada en los nuevos habitantes de la isla y en sus nuevas formas de relacionarse en el tiempo y el espacio.

Específicamente y en el caso de las tres constelaciones analizadas en este artículo, observamos que estas se tensionan desde variadas combinaciones. Si bien la primera constelación está desapareciendo, las otras dos persisten. Una forma importante y acaso subrepticia hasta aquí, acontece en el plano político neoliberal asociado a la movilidad de la última constelación. Sin embargo, esto se advierte en la modulación de las tres constelaciones, como gobierno de lo periférico o aislado bajo la creencia del progreso individual. Es decir, el movimiento estratégico en cada época es elaborado desde el progreso ante el aislamiento isleño. Sin embargo, en las constelaciones se muestra como en este desplazamiento de tipo productivo hacia lo exterior o diferente que isla, se termina contrariamente propiciando el aislamiento y el abandono territorial, la mercantilización de las prácticas de trabajo y la posterior devaluación del suelo para el desarrollo de nuevas movilidades y expresiones turísticas.

A partir de este análisis, fue posible mostrar como el habitar chilote actual esta tensionado desde la entrada al archipiélago de una movilidad capitalista donde se pierde la autonomía propia de los isleños en sus movimientos y prácticas cotidianas, lo que hace perder también su capacidad para determinar su propia movilidad. Las movilidades actuales parecen estar dominadas por otros tiempos (el del trabajador asalariado), parecen ser confinadas, más tediosas y desarraigadas (recorrer grandes distancias en transporte público para trabajar en una fábrica mal pagados), estructurando un habitar desligado de la naturaleza y anclado en las periferias empobrecidas de las ciudades chilotas.

Finalmente, las rupturas presentes en las constelaciones dicen relación con el desarrollo y tensión de la vida móvil tradicional y la legitimidad de lo individual en el espacio archipelágico moderno. Las constelaciones de la movilidad presentadas aquí visibilizan un elemento importante del habitar chilote, es decir, la tendencia a ver más allá de la isla, como emprendimiento personal y libertad privada en la movilidad. Esta creencia asociada a lo tradicional, desde el remero en adelante, se ha tensionado pero convivido desde la modernidad, la técnica y sus objetos. De todas formas, tal como se señaló en este artículo, existe una complementariedad (Barton, Pozo et al. 2013) en relación a las formas de movilidad en la constante combinatoria y superposición de las prácticas de cada constelación.

Agradecimientos: Los autores agradecen a la Comisión Nacional de Investigación Científica y Tecnológica (Conicyt) y al programa Fondecyt por el financiamiento del proyecto de postdoctorado 3140115 del cual surgen parte de los resultados aquí presentados. Se agradece también a los evaluadores de esta revista por la rigurosidad y precisión de sus comentarios, en el proceso editorial.

\section{Referencias Citadas}

Adey, P. 2009. Mobility. Routledge, Londres.

Anabalón, P. 2017. Territorios de Conectividad y el Proyecto de Construcción del Puente de Chacao. Aproximación Exploratoria a la Movilidad y los Discursos de Desarrollo de los Habitantes de Pargua y Chacao. Tesis para optar al título de magister en desarrollo humano a escala local y regional, Universidad de la Frontera, Temuco.

Baldacchino, G. 2003. The Coming of Age of Island Studies. Canada Research Chair in Island Studies, University of Prince Edward Island, Prince Edward Island.

Baldacchino, G. 2004. Island Studies Comes of Age. Tijdschrift voor Economische en Sociale Geografie 95:272-284.

Baldacchino, G. 2007a. A World of Islands. Charlettetown. PEI, Institute of Island Studies, Prince Edward Island.
Baldacchino, G. 2007b. Fixed links and the engagement of islandness: reviewing the impact of the Confederation Bridge. The Canadian Geographer / Le Geographe Canadien 51:323336.

Baldacchino. G. y E. Clark 2013. Guest editorial introduction: Islanding cultural geographies. Cultural Geographies 20:129-134.

Barton, J., Á. Román, A. Salazar y B. McPhee 2013. ¿Son nuevas las ruralidades de Chiloé? Transformaciones territoriales y la modernización de los modos de vida rurales. Anales de la Sociedad Chilena de Ciencias Geográficas. El Mundo Rural y sus Problemáticas. pp. 197-203. Universidad de Tarapacá, Arica.

Barton, J., R. Pozo, Á. Román y A. Salazar 2013. Reestructuración urbana de un territorio glocalizado: una caracterización del crecimiento orgánico en las ciudades de Chiloé, 1979-2008. Revista de Geografía Norte Grande 56:121-142. 
Bell, M y G. Osti 2010. Mobilities and ruralities: An introduction. Journal Compilation 2010 European Society for Rural Sociology 3:199-204.

Berry, B. 1985. Islands of Renewal in Seas of Decay. En The New Urban Reality, editado por E. Peterson, pp. 69-96. Brookings, Washington, D.C.

Bissell, D. 2009. Conceptualising differently-mobile passengers: geographies of everyday encumbrance in the railway station. Social \& Cultural Geography 10: 173-195.

Calonge, F. 2014. Movilidades capitalistas e identidades subalternas. Te mueves porque te mueven. Revista Sociológica México 29:129-164.

Clark, E. 2007. Island gentrification and space wars. En A World of Island. En Island Studies Reader, editado por G. Baldacchino, pp. 481-510. Academic and Institute of Island Studies, Malta.

Clifford, J. 1997. Routes: Travel and Translation in the Late Twentieth Century. Harvard University Press, Cambridge.

Cresswell, T. 2006. On the Move: Mobility in the Modern Western World. Routledge, New York.

Cresswell, T. 2010. Towards a politics of mobility, Environment \& Planning 28:17-31.

De Mattos, C. 2006. Modernización capitalista y transformación metropolitana en América Latina: cinco tendencias constitutivas. En América Latina: Cidade, Campo e Turismo, editado por A Geraiges, M. Arroyo, M.L. Silveira, pp. 41-73, CLACSO, São Paulo.

Floysand, A. y Á Román 2008. Industria salmonera, sistemas de innovación y desarrollo local. El punto de vista de las municipalidades de Chiloé. The Norwegian Research Council Departamento de Geografía, Universidad de Bergen, Bergen.

Gajardo, P. 2015. Construcción de género en la realidad insular. www.academia.edu.Gajardo_P._2015 (7 Noviembre)

Glass, R.1964. Aspects of Change in London. University Centre for Urban Studies, London.

Gobantes, C. 2011. Migraciones Laborales en un Archipiélago en Transformación. Chiloé ante al Desarrollo de la Salmonicultura. Tesis para optar al grado de Antropólogo Social. Facultad de Ciencias Sociales, Universidad de Chile, Santiago.

Gundermann, H., H. González y L. De Ruyt 2009. Migración y movilidad mapuche a la Patagonia Argentina. Magallania 37:2135 .

Hannam, K., M. Sheller y J. Urry 2006. Mobilities, immobilities, and moorings. Mobilities 1:1-22.

Henríquez C, et.al. 2015. Primera Encuesta Provincial CESCH. Chiloé y sus prioridades. Centro de Estadios Sociales de Chiloé CESCH, Chiloé.

Jordán, R. y R. Martínez 2009. Pobreza y Precariedad Urbana en América Latina y el Caribe. Colección Documentos de Trabajo. CEPAL, Santiago.

King, R. 2009. Geography, islands and migration in an era of global mobility. Island Studies Journal 4:53-84.

Macé, J.C. 2010. Dinámicas de sistemas de género en Chiloé Central, o la cuadratura de los ciclos. Documento de Trabajo $\mathrm{N}^{\circ}$ 63, Programa Dinámicas Territoriales Rurales. Rimisp, Santiago.
Mancilla, C. y R. Rehbein 2007. De Viajes y Retornos: Una Aproximación al Estudio del Imaginario de la vida Errante en el Chiloé de la Primera Mitad del Siglo XX. Tesis para optar al título profesional de Antropólogo(a) y grado académico de Licenciado(a) en antropología Universidad Austral de Chile, Valdivia.

Mansilla, S. 2006. Chiloé y los dilemas de su identidad cultural ante el modelo neoliberal chileno: la visión de los artistas e intelectuales. Alpha 23:9-23.

Mansilla, S. 2009a. Los territorios abandonados. Una reflexión sobre las identidades fantasmas (a propósito del despoblamiento de algunas islas del archipiélago de Quinchao). En Territory and Development. Dilemmas of Regional Modernity, editado por M. Czery, A. Vallejos Romero, J. Park Key, pp 120-136. University Press, Warsaw.

Mansilla, S. 2009b. Mutaciones culturales de Chiloé: los mitos y las leyendas en la modernidad neoliberal isleña. Convergencia Revista de Ciencias Sociales 51:271-299. Universidad Autónoma del Estado de México.

Mondaca, E. 2016. El archipiélago de Chiloé y los contornos inciertos de su futuro. Coloniedad y saqueo extravista. http://www. territoriocesch.com/general-1/ijyalka317/(7 Noviembre 2017)

Montiel, D. 2007. El influjo de los chilotes en la Patagonia.http:// www.virginia-vidal.com/publicados/crónicas/printer_234.shtr (8 Enero 2018)

Sheller, M. y J. Urry 2006. The new mobilities paradigm. Environment and Planning 38:207-226.

Ther, F. 2011. Configuraciones del tiempo en el mar interior de Chiloé y su relación con la apropiación de los territorios marítimos. Desenvolvimento e Meio Ambiente 23:67-80.

Ther, F. 2008. Prácticas cotidianas e imaginarios en sociedades litorales: el sector de Cucao, isla grande de Chiloé. Chungara Revista de Antropología 40:67-80.

Urry, J. 2007. Mobilities. Polity Press, Cambridge.

Vannini, P. 2011a. Constellations of (in) convenience: disentangling the assemblages of Canada's west coast island mobilities. Social \& Cultural Geography 12:471-492.

Vannini, P. 2011b. Constellations of ferry (im) mobility: Islandness as the performance and politics of insulation and isolation. Cultural Geographies 18: 249-271.

Vannini, P. 2012a. Ferry Tales: Mobility, Place, and Time on Canada's West Coast. Routledge, New York.

Vannini, P. 2012b. Non-Representational Research Methodologie. http://www.academia.edu/5217885/Nonrepresentational_ Theory_and_Methodologies_Re-envisioning_Research (10 Mayo 2016).

Vannini, P., G. Baldacchino. L. Guay, S.A. Royle y P.E. Steinberg 2009. Recontinentalizing Canadá: Arctic ice's liquid modernity and the imagining of a Canadian archipelago. Island Studies Journal 4:121-138.

Watts, L. 2008. The art and craft of train travel. Social \& Cultural Geography 9:711-726.

Yáñez, C. 2011. De remeros a pasajeros: memorias de viajes y cambios sociales en una isla. Revista de Historia Regional y Local 3:231-252. 